\title{
Experimental investigation on stern-boat deployment system and operability for Korean coast guard ship
}

\author{
Ho Hwan Chun ${ }^{1}$, Moon Chan Kim ${ }^{1}$, Inwon Lee ${ }^{2}$, Kookhyun Kim ${ }^{3}$ \\ Jung Kwan Lee ${ }^{4}$ and Kwang Hyo Jung ${ }^{5}$ \\ ${ }^{I}$ Department of Naval Architecture \& Ocean Engineering, Pusan National University, Busan, Korea \\ ${ }^{2}$ GCRC-SOP, Pusan National University, Busan, Korea \\ ${ }^{3}$ Department of Naval Architecture, Tongmyong University, Busan, Korea \\ ${ }^{4}$ Hanjin Heavy Industries \& Construction Co. Ltd. , Busan, Korea \\ ${ }^{5}$ Department of Naval Architecture \& Ocean Engineering, Dong-Eui University, Busan, Korea
}

\begin{abstract}
The stern boat deployment system was investigated to evaluate the capability of launching and recovering rigid hull inflatable boat (RHIB) via the stern ramp. The main parameters to launch and recover RHIB were tested at the design stage. The combined hydrodynamic effect of the stern wake and the water jet flow made it difficult to maintain the maneuvering and sea-keeping ability of RHIB approaching to the stern ramp. The safe recovery course was proposed to maintain the directional control of RHIB and to reduce the combined hydrodynamic effect in the transom zone. To evaluate the feasibility of RHIB recovery, the stern sill depth was measured in various conditions and the ramp availability time was obtained. Also, the experimental percent time operability (PTO) test was performed by the number of successive launching and recovering operations.
\end{abstract}

KEY WORDS: Ship motion; Sea state; Stern ramp; Wake; Launch; Recovery; Sill depth; Ramp availability time.

\section{INTRODUCTION}

An oceangoing cutter integrated system to launch and recover small boat is increasing to effectively complete their missions in seaway instead of the traditional side-davit system with single or dual falls. And, a rigid hull inflatable boat (RHIB) is integrally designed to deploy via a stern ramp and fit into a mother ship. After the late 1980's, the researches has been conducted to propose the various boat deployment system and design criteria. In the mid-1990's, U.S. Coast Guard has initiated to develop design criteria and evaluate stern deployment systems for the ships up to $120 \mathrm{~m}$ length. Even though several investtigations associated to the stern launching and recovery system has been performed, those results have been protected to release to the public. Sheinberg et al. (2001) visited seven vessels of various sizes to determine the effectiveness of their deployment systems. This investigation divided stern launching systems into two distinct types: the docking well and the ramp, and small boat supporting systems into three ways: shape the ramp to suit the boat hull, provide fixed longitudinal supports for the hull, and provide a movable cradle. Sheinberg et al. (2003) performed a worldwide assessment of vessels with stern deployment capability and determined their design criteria and operating characteristics. No analytical and numerical approach has been applied in the design stage, and the design criteria for designers and engineers have not existed. They took dedicated efforts reviewing existing system evaluation methodology for stern deployment of RHIB and a fast response craft

Corresponding author: Kwang Hyo Jung

e-mail:khjung@deu.ac.kr 
(FRC) from various sizes of cutters, and provided three criteria sets: the mother ship motion criteria, the relative motion of the stern ramp sill, and the ramp availability criterion. Clauss and Kauffeldt (2006) utilized the numerical approach based on the volume of fluid (VOF) and Reynolds Averaged Navier Stokes Equation (RANSE) to analyze local flow phenomena inside the dock and suggested the optimized dock shape.

In this study, the experimental investigation in the towing tank was performed to evaluate the capability launching and recovering RHIB via the stern ramp at the transom of the mother ship. The mother ship was propelled by the water-jet propulsion system, and RHIB had an outboard engine driven and a radio controlled planning model. The experiments in the towing tank have been performed with various ocean conditions: two sea states, two speeds of mother ship, and two wave directions. The stern ramp utilized a downward hinging stern gate and was integrally designed to be able to launch and recover RHIB during seagoing missions. The sea-keeping tests were conducted for the mother ship and RHIB including their relative motion test at 5 different locations. The main parameters of the stern deployment system that could significantly influence the ability to launch and recover RHIB safely such as the ramp sill depth, the ramp surface, the ramp shape, the capture mechanism, the ramp side and clearance, etc, have been tested at the design stage and modified to improve the ability and safety of the stern boat deployment system. The combined hydrodynamic effect of the stern wake and wave and the water jet flow from the water-jet propulsion system of the mother ship made it difficult to maintain the maneuvering and sea-keeping ability when RHIB approached to the stern ramp. The safe recovering course and the RHIB's recovery speed range were proposed to maintain the directional control of RHIB and to reduce the combined hydrodynamic effect near the mother ship stern. For the evaluation of the feasibility and operational effectiveness of launching and recovering RHIB, the relative vertical motion of the ramp sill was measured in a seaway and the period of time during the ramp sill immersed in the water, called the ramp availability time, was obtained. Also, the experimental percent time operability (PTO) test of the number of successive launching and recovering operations was carried out in the towing tank.

\section{KCG FAST PATROL SHIP}

It is essential of ship-deployed boats to perform the successive seagoing missions of Korean Coast Guard (KCG). KCG is building the 500 ton class fast patrol ship shown in Fig. 1 equipped the stern boat deployment system launching and recovering RHIB via the stern ramp that are integrally designed into the transom of the mother ship instead of the traditional side-davit system. The patrol ship have four water-jets of which two buster water-jets are equipped to operate at the maximum speed (35 knots) and RHIB is driven by two outboard engines (two 150PS engines). Fig. 2 and Fig. 3 show body plans of KCG fast patrol vessel and RHIB.

Sheinberg et al. (2003) categorized presently operating stern deployment systems with variations on arrangement details into four stern ramp types: well dock, fixed ramp, hinged ramp, and extended ramp. The extended stern ramp system was chosen for 500 ton class fast patrol ship of KCG as shown in Fig. 4. The stern ramp was designed to suit the shape of RHIB and have successive rollers on the 3 rails along the bottom of RHIB from the inside surface of the stern gate to reduce the friction on

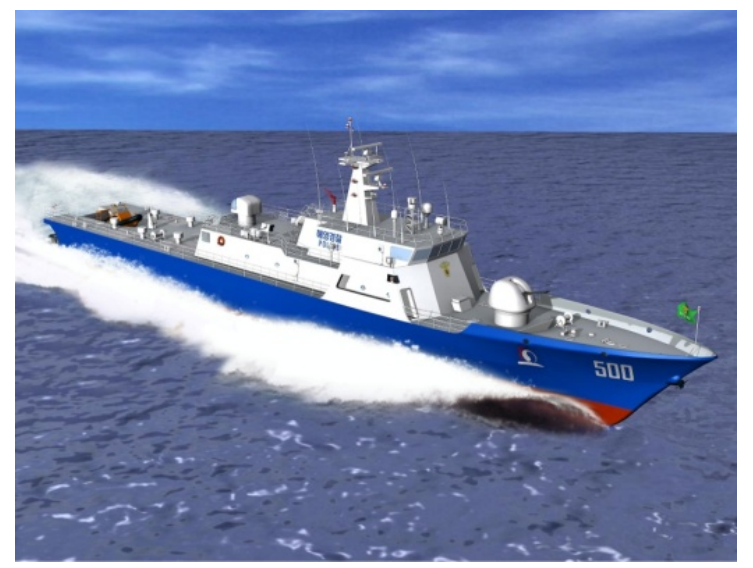

Fig. 1 Virtual reality image of KCG fast patrol vessel.

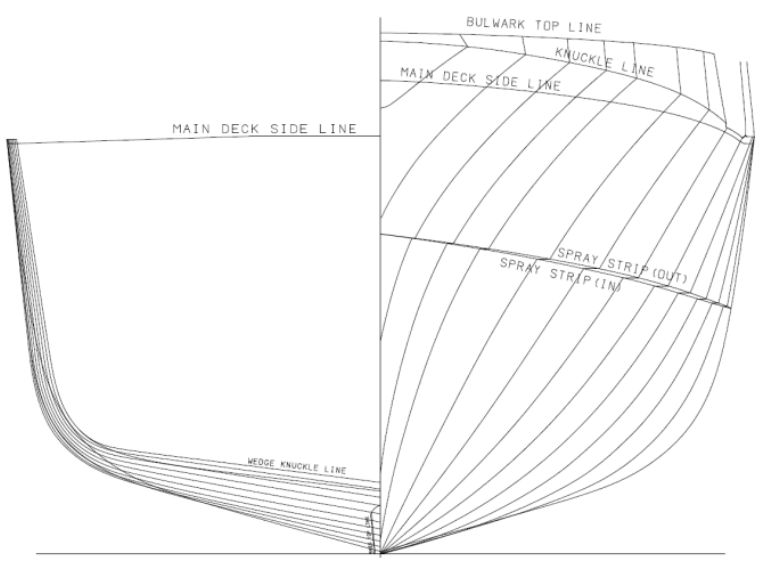

Fig. 2 Body plan of KCG fast patrol vessel. 
the sliding surface. The stern ramp gate was utilized the outward hinging door hydraulically powered. The ramp surface initially designed was supposed to support the bottom of RHIB stable sitting on the roller rail, but side rollers were not properly contacted to support the bottom of RHIB and the sharp transom edge of RHIB was occasionally stuck between rollers and roller support. So, the height of side rollers increased to be able to support the bottom of RHIB and the space between rollers along rails was reduced to avoid the obstruction of the sharp transom edge jammed between rollers and roller support.

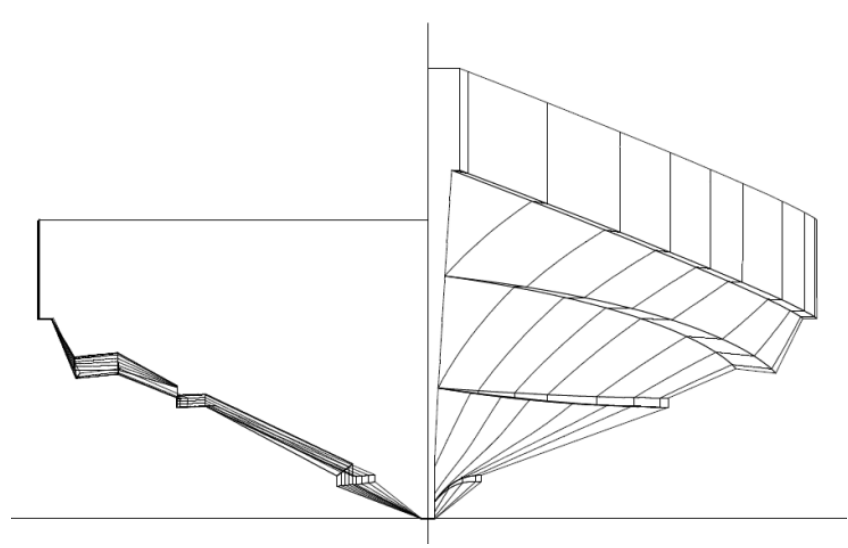

Fig. 3 Body plan of RHIB.

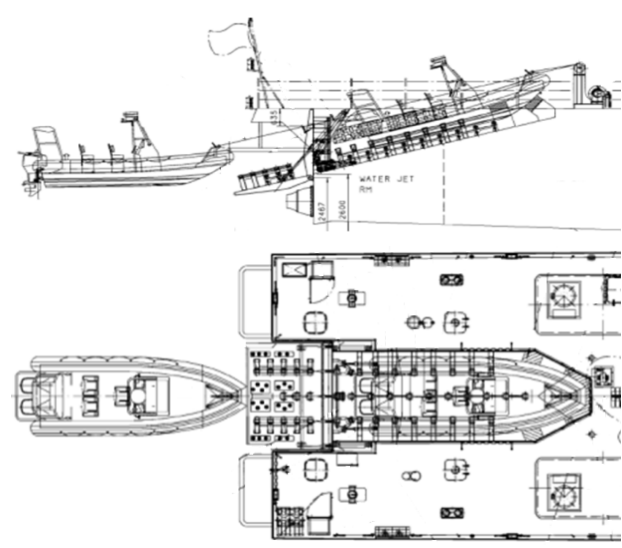

Fig. 4 Stern ramp on KCG fast patrol vessel.

One of the most important parameters of stern ramp operability is the stern sill depth variation which is the submerged depth at the aft end of the stern ramp. The stern sill depth variation determines the ramp availability time to recover RHIB and governs the probability of RHIB impacting on the ramp surface during the RHIB recovery. The stern sill depth was designed at $0.6 \mathrm{~m}$ being same with the draft of RHIB, which allowed that RHIB could drive closer to the transom in order to reach a winch cable to boat. Ramp slope is more important to launching than to recovery. Ramp slope of $15^{\circ}$ aided RHIB sliding down to launch without any assistance. To recover RHIB, a deck hand or a winch operator passes the winch cable to the bowman on RHIB. It is expected to be able to launch RHIB in relatively high sea states, but the recovery is certainly limited by the sea state and the cruising speed. If the sea state is too high for the safe recovery, the mother ship would guide RHIB to calmer water to complete the recovery. The launching and recovery of RHIB would proceed in near normal direction to the wave crest (head or following seas). The launching procedure is that the bowman makes the quick release hook and RHIB slides down the ramp and self-propels backward out of the transom. The recovery procedure is strongly dependent on the ability of a coxswain who should decide the time RHIB approaching to the stern ramp at the moment of the maximum sill depth. If the coxswain chooses the recovery moment, he accelerates RHIB into the opening stern gate and up to the ramp gate surface. Then, the winch cable is passed to the bowman who hooks it on RHIB, and RHIB is winched up the ramp to the stowed position.

\section{MODEL TEST}

Experimental test in model scale was carried out in the towing tank at Pusan National University, Busan, Republic of Korea, $100 \mathrm{~m}$ long, $8 \mathrm{~m}$ wide, $3.5 \mathrm{~m}$ deep, and $7 \mathrm{~m} / \mathrm{s}$ the maximum carriage speed. Multi-directional regular and irregular waves can be generated by the snake type wave maker having 23 plungers, which can cover the frequency range from 0.5 to $3.0 \mathrm{~Hz}$. The wave absorbing beach was installed to reduce the wave reflection at the end of towing tank. The model test was conducted using the 500 ton class fast patrol ship model as the mother ship and radio-controlled planing model as RHIB. The overall length of the mother ship and RHIB are $62.2 \mathrm{~m}$ and $6.5 \mathrm{~m}$, respectively, and principles are shown in Table 1.

The model of the mother ship and RHIB was manufactured by FRP at the scale ratio of 1:13 as shown in Fig. 5. Test conditions was two speeds ( 5 knots and 8 knots), two heading angles $\left(0^{\circ}\right.$ and $\left.180^{\circ}\right)$, and two sea states $(3$ and 4$)$. The mother ship was self-propelled by two water jet propulsion systems which operated at $950 \mathrm{rpm}$ and $1440 \mathrm{rpm}$ for 5 knots and 8 knots, respectively, of cruising speeds to launch and recover RHIB. During the tests in the towing tank, the mother ship was allowed to freely heave, roll, and pitch motions. Because the towing carriage is allowed to run on the straight rails, two wave directions (heading and following seas) were tested. As the space on RHIB model was limited to install two outboard engines, RHIB 
Table 1 Principles of KCG 500 ton class fast patrol vessel.

\begin{tabular}{|c|c|c|}
\hline Loading condition & Sea trial & Full load \\
\hline $\mathrm{L}_{\mathrm{OA}}(m)$ & 62.2 & 62.2 \\
\hline $\mathrm{L}_{\mathrm{PP}}(m)$ & 56.3 & 56.4 \\
\hline $\mathrm{L}_{\mathrm{WL}}(m)$ & 56.3 & 56.4 \\
\hline $\mathrm{B}(m)$ & 9.1 & 9.1 \\
\hline $\mathrm{D}(m)$ & 5 & 5 \\
\hline Displacement $\left(m^{3}\right)$ & $601.2(w / B . K)$ & $638.4(w / B . K)$ \\
\hline $\mathrm{L}_{\mathrm{CB}}$ & $-8.70 \%$ & $-8.69 \%$ \\
\hline $\mathrm{C}_{\mathrm{B}}$ & 0.425 & 0.451 \\
\hline
\end{tabular}

model was the radio-controlled free-sailing model having one outboard engine driven by the brushless motor (190PS in full scale) and directed by the servo motor, which were controlled by six-channel remote controller (6EXHP-PCM). Because of the condition of being limited in the towing tank, person who controlled the RHIB was standing on the towing carriage, that is, he was looking at a camera view from the fast patrol ship model.
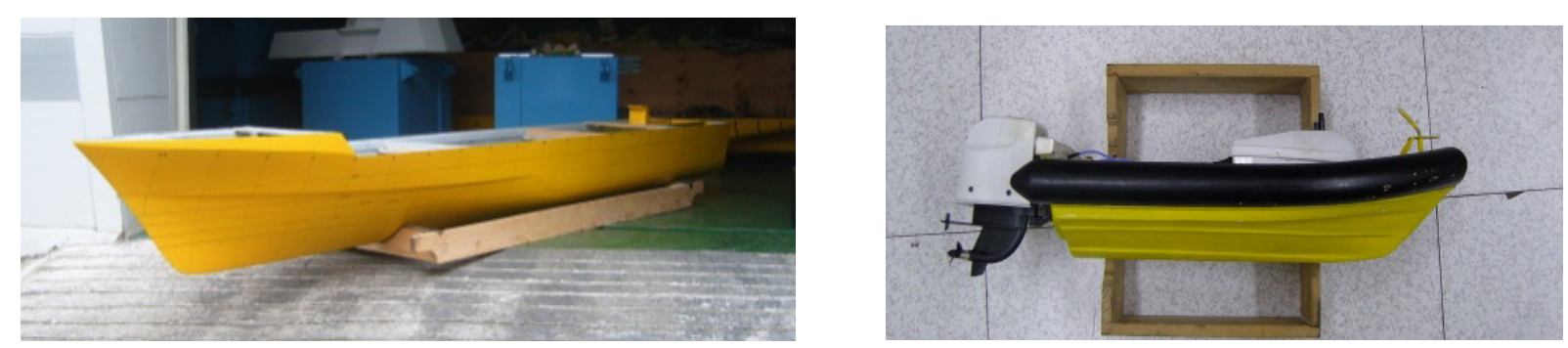

Fig. 5 Model of KCG 500 ton class fast patrol vessel and RHIB.

Sea state 3 and 4 simulated the irregular waves using Bretschneider Spectrum Eq. (1) of which spectrum are shown in Fig. 6.

$$
S(\omega)=\frac{H_{s}{ }^{2}}{4 \pi}\left(\frac{2 \pi}{T_{m}}\right)^{4} \omega^{-5} \exp \left(-\frac{1}{\pi}\left(\frac{2 \pi^{2}}{T_{m} \omega}\right)^{4}\right)
$$

where $\omega$ is the wave circular frequency, $H_{s}$ the significant wave height, $T_{m}$ the modal wave period.

Table 2 Wave spectrum variables.

\begin{tabular}{|c|c|c|}
\hline \multirow{2}{*}{ Sea state } & \multicolumn{2}{|c|}{ Spectrum parameters } \\
\cline { 2 - 3 } & $H_{s}(m)$ & $T_{m}(s)$ \\
\hline 3 & 0.88 & 7.5 \\
\hline 4 & 1.8 & 8.8 \\
\hline
\end{tabular}

The double-wired resistance-type wave gauge was used to measure the free surface elevation at a sampling rate of $100 \mathrm{~Hz}$, of which the total error of linearity, repeatability, and hysteresis was less than $0.5 \%$ of maximum measurement range $(20 \mathrm{~cm})$ obtained from repeated calibrations. The 6-degree of freedom ship maneuvering test rig was employed to measure the 6-degree motion of the mother ship, of which errors were less than $1 \%$ of maximum measurement ranges (heave: $\pm 30 \mathrm{~cm}$, roll and pitch: 
$\pm 45^{\circ}$, respectively) in each direction. Because the mother ship was towed by the towing carriage to keep the direction of head and following seas, its surging, swaying, yawing motions were not allowed. The 6-D motion optical tracking system (RODYM DMM-6D) in Fig. 7 was utilized to obtain the motion of RHIB propelled by the own outboard engine, which had the high accuracy of $0.1 \mathrm{~mm}$ in each direction.

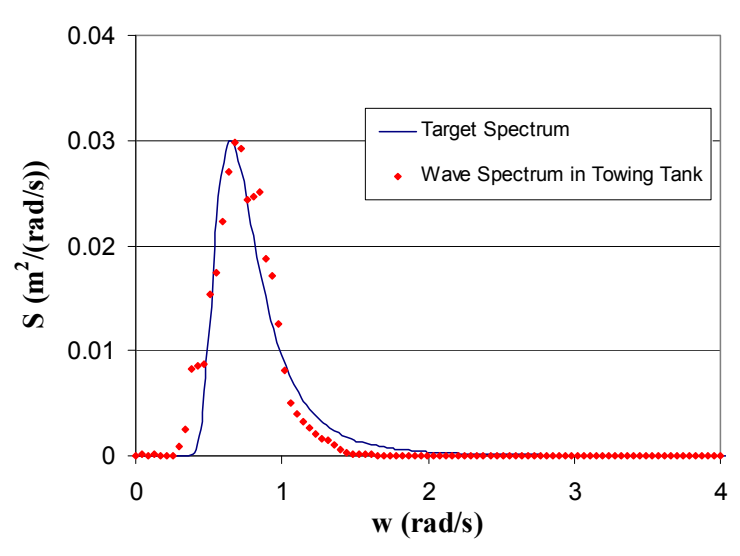

(a) Sea state 3 .

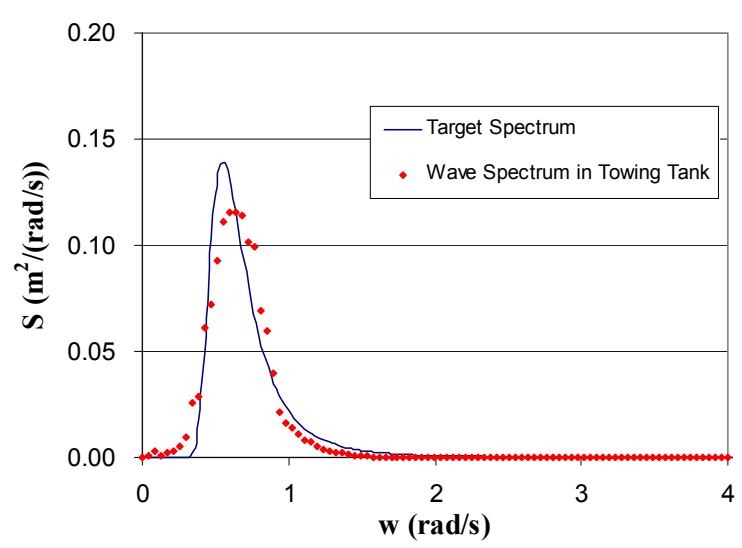

(b) Sea state 4 .

Fig. 6 Wave spectrum for sea state 3 and 4.

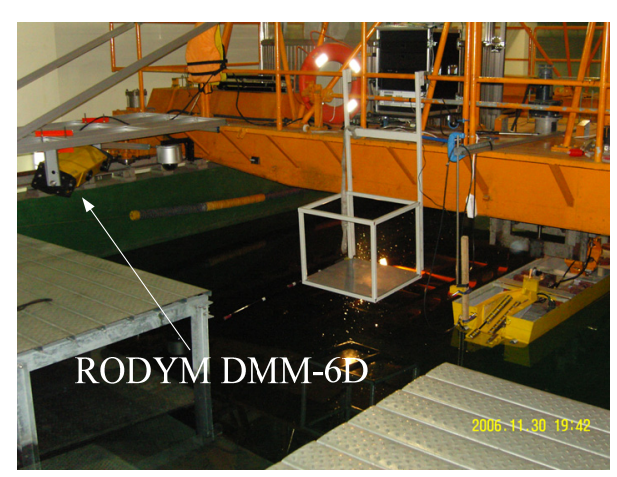

Fig. 7 6-D motion optical tracking system

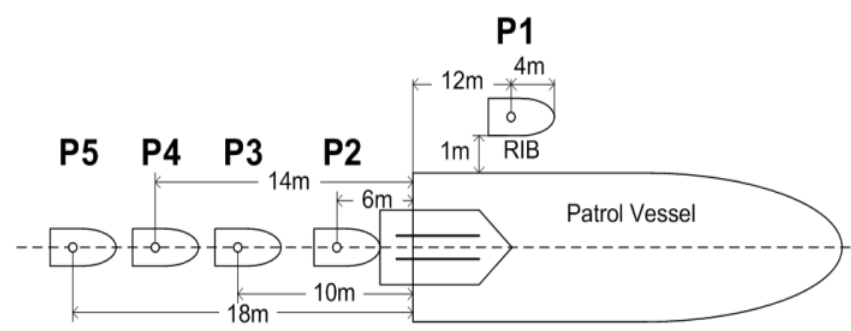

Fig. 8 Locations for RHIB relative motion test.

(RODYM DMM-6D) on the towing carriage.

The ship motion tests were conducted with the mother ship alone and RHIB at five different positions (Fig. 8) where located four different distances from the stern gate and one position side of the mother ship to obtain the relative motion characteristics of RHIB influenced by the mother ship. The experiments with the mother ship and RHIB launching from and recover to the stern ramp were performed with various conditions combined the test conditions mentioned above to determine the ramp operability. The following data were obtained from the model test in the towing tank:

- Three degree of motions (heave, pitch, and roll) of mother ship at the center of gravity at the conditions of two speeds, two sea states, two wave directions.

- Three degree of motions (heave, pitch, and roll) of mother ship at the center of gravity with the 7 wave directions at the zero speed and two sea states.

- Vertical acceleration at the stern gate sill which computed from pitch and heave motions data.

- Stern sill depth variations which computed from pitch and heave motion data and the free surface elevation measured at the stern gate sill.

- Relative motion test of RHIB at the 5 different locations near the transom.

- Stern wave profile from the stern sill.

- Launch and recovery time duration more than 10 times for each case. 
- Speed and course of RHIB leaving from and entering to the stern ramp.

- Experimental PTO tests for each case.

These model test results were used to verify the stern-ramp deployment ability of the mother ship and RHIB, which were compared with the suggested design criteria for the mother ship motion and the ramp availability time. Based on the model test results, also, the hydrodynamic phenomena combined the stern wake and wave and the water-jet flow at the transom area was investigated to minimize those hydrodynamic influences and keep the maneuvering and sea-keeping ability of RHIB during launching and recovering processes.

\section{DESIGN CRITERIA FOR STERN DEPLOYMENT SYSTEM}

Three criteria were proposed to evaluate the performance of stern-boat deployment system (Sheinberg et al., 2003). The first was the mother ship motion criteria, which are same with the side-davit deployment system. The second was the relative variation of the stern ramp sill in and out of the water, which was represented into the ramp availability criterion. The third was for the deployed boat and its capability to affect a successful recovery onto the stern ramp of which criteria can be evaluated by model or full scale test with instrumentation on the small boat or the application of impact loads time-domain models. They purposed the seven criteria (Table 3) for stern-ramp deployment system of which the mother ship motion-limiting criteria were adopted from side-davit boat deployment system (Minnick et al., 1999), the minimum average ramp availability time were obtained from the survey of ramp-equipped ships, and the relative sway and vertical motions at the ramp entrance was computed from the model tests. In this study, the lateral acceleration at the boat station and the sway at the ramp entrance are not included because the model test for the launching and recovery of RHIB would be carried out at near head or following seas.

Table 3 Operational criteria for stern ramp deployment.

\begin{tabular}{|c|c|}
\hline Criterion & Limit \\
\hline Roll motion & $8.0^{\circ} \mathrm{SSA}$ \\
\hline Pitch motion & $2.5^{\circ} \mathrm{SSA}$ \\
\hline Vertical acceleration at boat station & $0.2 \mathrm{~g}$ \\
\hline Lateral acceleration at boat station & $0.2 \mathrm{~g}$ \\
\hline Ramp availability time & $\mathrm{T}_{\mathrm{RA}}=5 \mathrm{~s}$ \\
\hline Relative vertical motion at the ramp entrance & $1.20 \mathrm{~m} \mathrm{rms}$ \\
\hline Sway at the ramp entrance & $0.75 \mathrm{~m} \mathrm{rms}$ \\
\hline
\end{tabular}

\section{EXPERIMENTAL RESULTS}

\section{Sea-keeping test of mother ship and RHIB}

Sea keeping test of the mother ship was conducted for seven wave directions (shown in Fig. 9) with the $30^{\circ}$ interval from the following sea $\left(0^{\circ}\right)$ to the heading sea $\left(180^{\circ}\right)$ at the zero speed condition. Fig. 10 shows the significant single amplitude (SSA) values of three motions (pitch, roll, and heave) for Sea State 3 and 4 with the function of wave directions. The pitch motion SSAs from the motion test at zero speed satisfied the design criteria $\left(2.5^{\circ}\right)$ for five wave directions $\left(0^{\circ}, 60^{\circ}, 90^{\circ}, 150^{\circ}, 180^{\circ}\right)$ in Sea State 3 and only one wave direction $\left(90^{\circ}\right)$ in Sea State 4.

Roll motion SSAs of six wave directions except the beam sea $\left(90^{\circ}\right)$ condition were less than the limitation of criteria $\left(8^{\circ}\right)$ in Sea State 3 and four wave directions $\left(0^{\circ}, 30^{\circ}, 150^{\circ}, 180^{\circ}\right)$ were under the design criteria in Sea State 4. Even though this motion test was performed at the zero speeds, the sea-keeping characteristics of the mother ship could be obtained. The motions of the mother ship alone cruising with 5 and 8 knots were measured at head and following sea conditions. SSA values of three motions (pitch, roll, and heave) are represented in Table 4 and 5. SSAs of all motions at 8 knots are less than those at 5 knots for 
both wave directions. Because the motion tests were performed for the head and following seas, SSAs of the roll motion were very small. From the zero speed motion tests results, the roll motion would be expected to satisfy its criteria $\left(8^{\circ}\right)$ at wave directions of $0^{\circ}, 30^{\circ}, 150^{\circ}$, and $180^{\circ}$ as shown in Fig. 10.

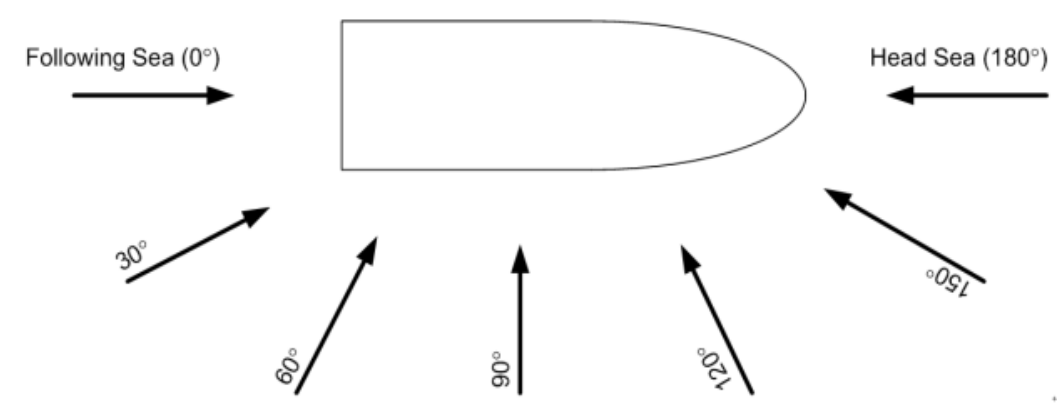

Fig. 9 Definition of heading angle.

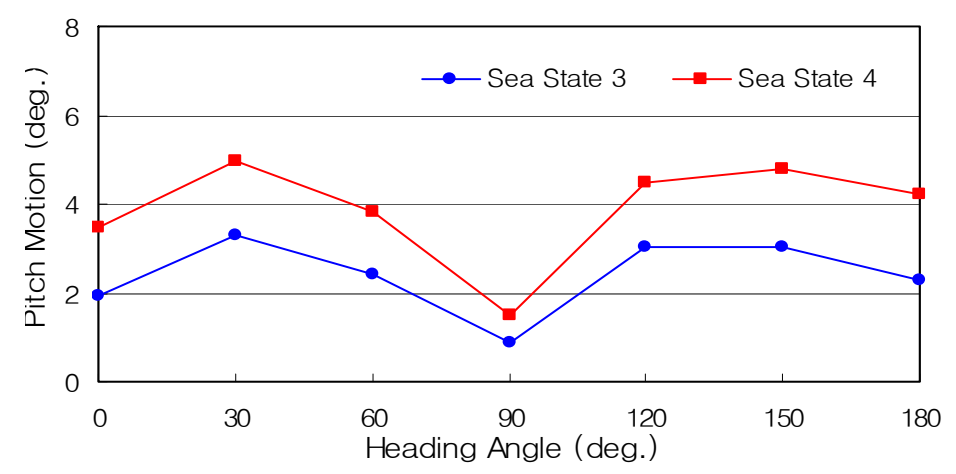

(a) Pitch motion.

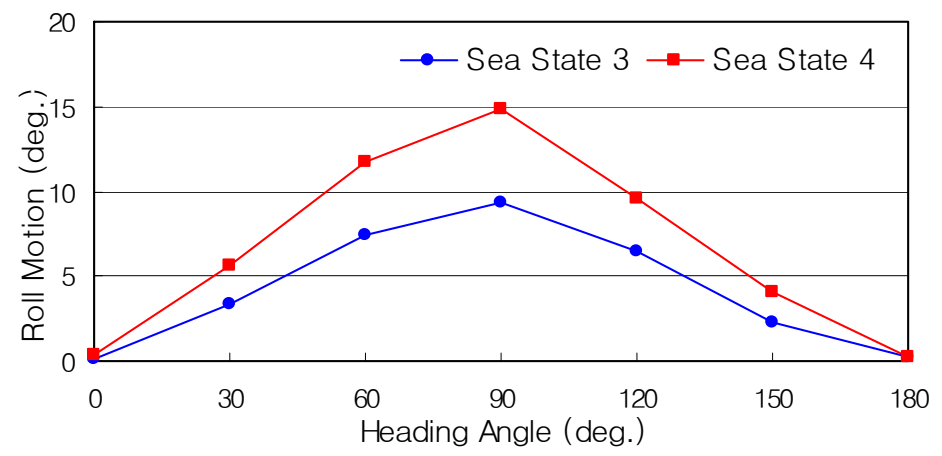

(b) Roll motion.

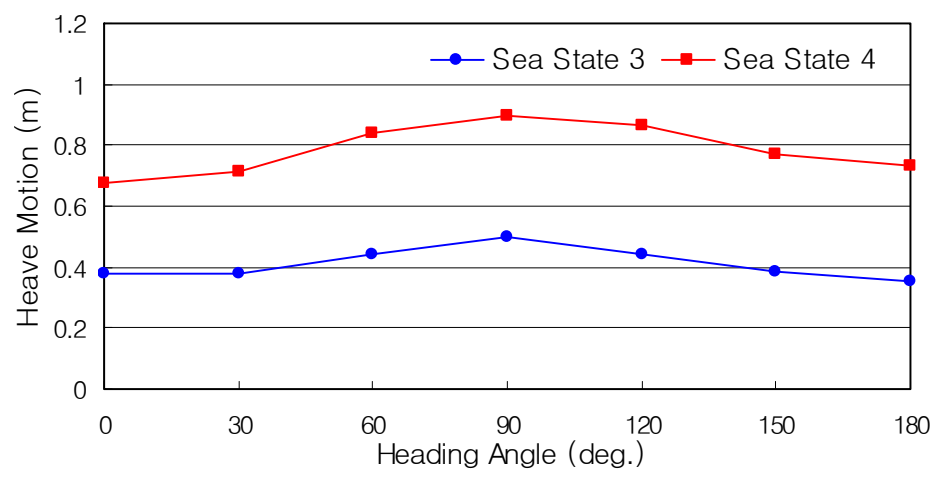

(c) Heave motion.

Fig. 10 SSA for motions in sea state 3 and 4 . 
Results of the pitch motion did not exceed the criteria $\left(2.5^{\circ}\right)$ in Sea State 3, but those were larger than the criteria in Sea State 4 for both speeds. Note that the pitch motion, the number in the parentheses, was decreased when the stern gate opened and the water jet operated. It might be caused by increasing the damping effect for the pitch motion resulted from the stern gate opening and the water jet operating. However, SSA values were still greater than its criteria. The vertical acceleration at the stern gate sill was computed by the central difference method using the vertical motion of the stern gate sill calculating from heave and pitch motions. All SSA values of the vertical acceleration at head and following sea conditions in Table 6 are under the criterion, $0.2 \mathrm{~g}$, at the boat station.

The motion test for RHIB alone and the RHIB relative motion test at five locations from the mother ship were carried out by the 6-D motion optical tracking system (RODYM DMM-6D). Fig. 8 shows five locations where the RHIB relative motion test was performed for conditions of two Sea State ( 3 and 4), two speeds ( 5 and 8 knots), and two wave angles (head sea, $0^{\circ}$, and following sea, $180^{\circ}$ ). The results of the RHIB relative motion test are presented in Table 7.

Table 4 SSA for each motion at head sea condition (( ): Results with water jet running and open stern gate).

\begin{tabular}{|c|c|c|c|c|}
\hline \multirow{2}{*}{ Sea state } & Speed (knots) & Pitch $\left(^{\circ}\right)$ & Roll $\left(^{\circ}\right)$ & Heave $(m)$ \\
\hline \multirow{2}{*}{3} & 5 & $2.29(2.00)$ & 0.26 & 0.31 \\
\cline { 2 - 5 } & 8 & $1.95(1.69)$ & 0.25 & 0.27 \\
\hline \multirow{3}{*}{4} & 5 & $4.20(3.27)$ & 0.53 & 0.82 \\
\cline { 2 - 5 } & 8 & $3.76(3.04)$ & 0.42 & 0.74 \\
\hline
\end{tabular}

Table 5 SSA for each motion at following sea condition (( ): Results with water jet running and open stern gate).

\begin{tabular}{|c|c|c|c|c|}
\hline Sea state & Speed $($ knots $)$ & Pitch $\left(^{\circ}\right)$ & Roll $\left(^{\circ}\right)$ & Heave $(m)$ \\
\hline \multirow{3}{*}{3} & 5 & $2.45(1.68)$ & 0.28 & 0.31 \\
\cline { 2 - 5 } & 8 & $2.10(1.53)$ & 0.29 & 0.27 \\
\hline \multirow{3}{*}{4} & 5 & $3.98(2.98)$ & 0.35 & 0.74 \\
\cline { 2 - 5 } & 8 & $3.77(2.83)$ & 0.43 & 0.70 \\
\hline
\end{tabular}

Table 6 SSA for sill vertical acceleration.

\begin{tabular}{|c|c|c|c|}
\hline \multirow{2}{*}{ Sea state } & Speed (knots) & Vertical acceleration \\
\cline { 2 - 4 } & & Head sea & Following sea \\
\hline \multirow{2}{*}{3} & 5 & $0.056 \mathrm{~g}$ & $0.047 \mathrm{~g}$ \\
\cline { 2 - 4 } & 8 & $0.074 \mathrm{~g}$ & $0.064 \mathrm{~g}$ \\
\hline \multirow{2}{*}{4} & 5 & $0.068 \mathrm{~g}$ & $0.068 \mathrm{~g}$ \\
\cline { 2 - 4 } & 8 & $0.075 \mathrm{~g}$ & $0.081 \mathrm{~g}$ \\
\hline
\end{tabular}

The position 1 is the location of the small boat deployment by the side davit system, and other 4 positions $(2,3,4$, and 5$)$ are on the recovery course to the stern ramp. Because it was hard to keep the fixed position of RHIB due to the strong water jet flow and the wave fluctuation, the motion test in Sea State 4 was not performed to protect the sensors of optical tracking system and the control system from wetting on them. In general, the heave motion in the following sea was larger than that in the head sea, but the roll and pitch motions in the following sea were smaller than those in the head sea. That reason would be that the wave reduction by the shelter effect in the head sea caused to decrease the heave motion and the stronger turbulent flow due to the stern wake behind the mother ship in the head sea resulted into larger pitch and roll motions than those in the following sea. 
Because of the more turbulent stern flow, the bigger stern wave, and the stronger water jet with faster speed ( 8 knots), it is hard of RHIB to keep the directional control on the recovery course between two water jet flows. The pictures of the relative motion test at position 3, Sea State 3 shows the difference of water jet flows between 5 and 8 knots in Fig. 11.

Table 7 SSA for each motion from relative motion test of RHIB.

5 knots in sea state 3

\begin{tabular}{|c|c|c|c|c|c|c|}
\hline \multirow{2}{*}{ Position } & \multicolumn{2}{|c|}{ Pitch (deg.) } & \multicolumn{2}{c|}{ Roll (deg.) } & \multicolumn{2}{c|}{ Heave $(m)$} \\
\cline { 2 - 7 } & $180^{\circ}$ & $0^{\circ}$ & $180^{\circ}$ & $0^{\circ}$ & $180^{\circ}$ & $0^{\circ}$ \\
\hline 1 & 3.21 & 1.81 & 1.65 & 2.01 & 0.47 & 0.68 \\
\hline 2 & 4.07 & 3.69 & 2.77 & 2.60 & 0.46 & 0.64 \\
\hline 3 & 2.11 & 2.04 & 1.65 & 1.81 & 0.51 & 0.53 \\
\hline 4 & 2.20 & 1.62 & 1.84 & 1.28 & 0.49 & 0.27 \\
\hline 5 & 2.28 & 2.06 & 1.65 & 1.15 & 0.48 & 0.33 \\
\hline
\end{tabular}

8 knots in sea state 3

\begin{tabular}{|c|c|c|c|c|c|c|}
\hline \multirow{2}{*}{ Position } & \multicolumn{2}{|c|}{ Pitch (deg.) } & \multicolumn{2}{c|}{ Roll (deg. } & \multicolumn{2}{c|}{ Heave $(m)$} \\
\cline { 2 - 7 } & $180^{\circ}$ & $0^{\circ}$ & $180^{\circ}$ & $0^{\circ}$ & $180^{\circ}$ & $0^{\circ}$ \\
\hline 1 & 2.91 & 3.94 & 4.84 & 3.49 & 0.44 & 0.60 \\
\hline 2 & 2.86 & 4.1 & 4.50 & 3.05 & 0.39 & 0.62 \\
\hline 3 & 4.35 & 2.04 & 4.10 & 4.16 & 0.56 & 0.30 \\
\hline 4 & 3.79 & 2.18 & 4.34 & 3.16 & 0.50 & 0.35 \\
\hline 5 & 2.93 & 2.42 & 3.02 & 3.07 & 0.39 & 0.28 \\
\hline
\end{tabular}

\begin{tabular}{|c|c|c|c|c|c|c|}
\hline \multirow{2}{*}{ Position } & \multicolumn{2}{|c|}{ Pitch (deg.) } & \multicolumn{2}{c|}{ Roll (deg.) } & \multicolumn{2}{c|}{ Heave $(m)$} \\
\cline { 2 - 7 } & $180^{\circ}$ & $0^{\circ}$ & $180^{\circ}$ & $0^{\circ}$ & $180^{\circ}$ & $0^{\circ}$ \\
\hline 1 & 4.53 & 3.04 & 2.60 & 1.40 & 1.03 & 0.90 \\
\hline 2 & 4.39 & 4.93 & 3.38 & 2.79 & 1.00 & 1.02 \\
\hline 3 & 3.39 & 3.04 & 2.29 & 3.33 & 0.99 & 0.73 \\
\hline 4 & 3.45 & 2.60 & 2.41 & 2.30 & 0.92 & 0.99 \\
\hline 5 & 3.45 & 1.91 & 2.28 & 2.22 & 0.94 & 0.94 \\
\hline
\end{tabular}

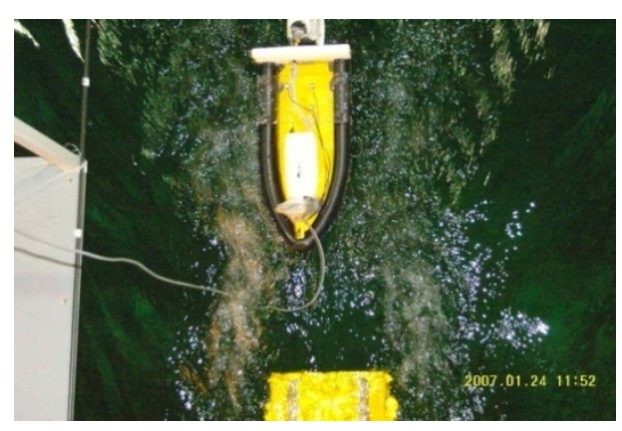

(a) 5 knots in sea state 3 at position 3 .

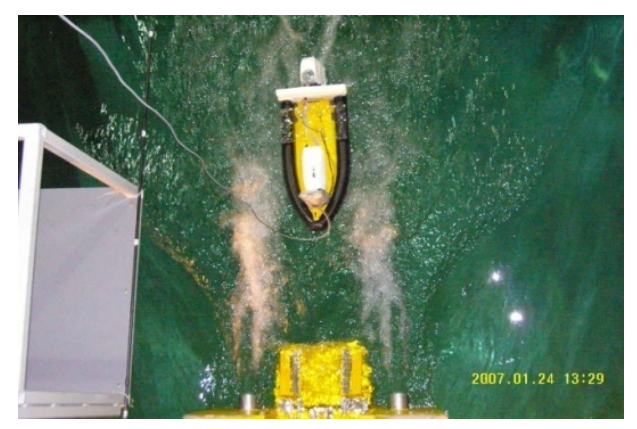

(b) 8 knots in sea state 3 at position 3 .

Fig. 11 RHIB relative motion test at following sea. 


\section{Stern wake and water jet flow effect}

The water jet flow increased the resistance of RHIB and reduced its maneuvering and sea-keeping abilities. In addition, the pitch and heave motions of the mother ship resulted into the vertical fluctuation of both water jets which caused the irregular jet flow combined with the stern wake and wave. Because higher Sea State increased the mother ship motion and caused the larger vertical fluctuation of the water jet, the water jet flow would disturb the RHIB return to the stern ramp. If RHIB would be directly hit by the water jet in the air, RHIB could be capsized or severely damaged. RHIB required to overcome the additional resistance due to the water jet flow in the transom area. To minimize the additional resistance resulting from the water jet flow, RHIB is recommended to access to the stern ramp through the middle of both water jets. Moreover, the stern wave was generated behind the mother ship and represented in Fig. 12 with the distance from the stern gate sill. When RHIB approached to the stern ramp, it met the zero up-crossing of the stern wave at approximately $8.5 \mathrm{~m}$ and $12 \mathrm{~m}$ locations for $5 \mathrm{knots}$ and $8 \mathrm{knots}$, respectively, from the stern ramp sill and the stern wave crest located at approximately $4 \mathrm{~m}$ and $5 \mathrm{~m}$ location for $5 \mathrm{knots}$ and 8 knots. Until the stern wave crest, RHIB would require more power to overcome the additional resistance to climb the stern wave slope. Because RHIB model passed though the stern wave by one 190 PS (in full scale) outboard engine, the full scale RHIB having two 150 PS outboard engines would go through the stern wave and wake region. After passing the stern wave crest, RHIB was expected to increase its speed because of sliding down the stern wave slope of the maximum angle of $3.4^{\circ}$ and $8.0^{\circ}$ for 5 and 8 knots, respectively, which helped RHIB reach to the stern ramp. However, a coxswain should carefully control RHIB having the extra speed increase at the down-crossing stern wave that may cause RHIB to impact on the stern ramp.
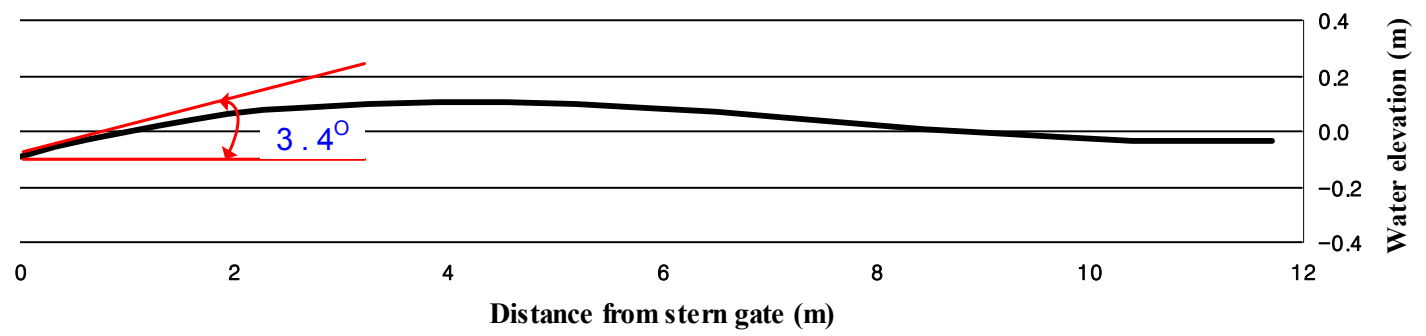

(a) 5 knots.

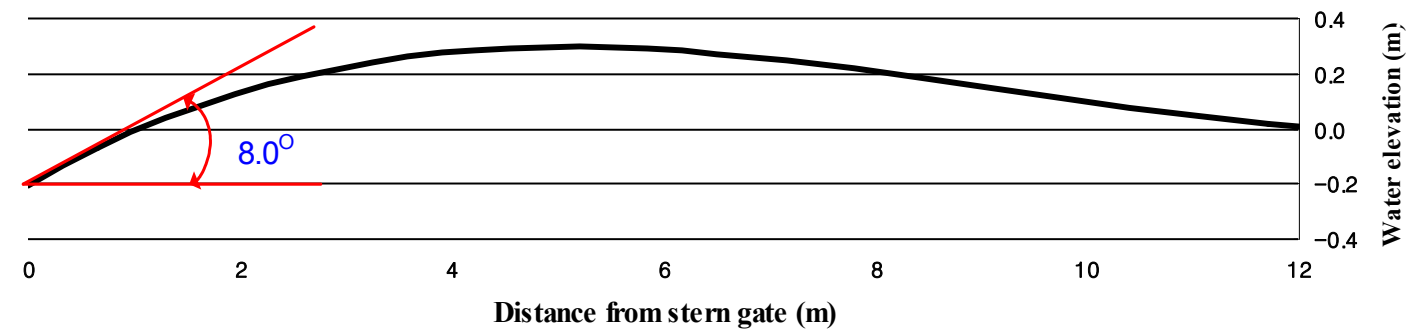

(b) 8 knots.

Fig. 12 Stern wave pattern from stern sill.

\section{Stern sill depth variation}

Several criteria such as pitch and roll motions, vertical acceleration, and so on, were suggested to categorize the safe performance of RHIB launching and recovery via the stern ramp. One of the most important criteria would be the stern sill depth variation, because it determined the ramp availability to avoid the direct impact on the stern ramp during the recovery procedure. The stern sill depth was defined as the vertical distance between the stern sill and the local water elevation to be positive when the stern sill rose above the water surface (Dalzell, 2003). A fragment of the stern sill depth variation $\left(\eta_{R}(t)\right)$ is sketched in Fig. 13.

The constant threshold, $h$, was set equal to the water depth over the stern sill with no-wave condition, also, same as the design draft $(0.6 \mathrm{~m})$ of RHIB. There is no specific rule to determine the constant threshold $(h)$ to define the ramp availability time. If the stern sill emerged over the water, RHIB may have damage due to hitting on the stern sill. For the minimum sill depth to avoid hitting the RHIB on the stern gate during the recovery, the constant threshold was determined to be same with the draft of 
RHIB on still water. Thus, if the stern sill depth $\left(\eta_{R}(t)\right)$ was positive, the stern sill was emerged over the water surface. The time durations that the stern sill depth exceeded zero and less than zero were denoted $\tau_{+}$and $\tau_{-}$, respectively. That is, the time

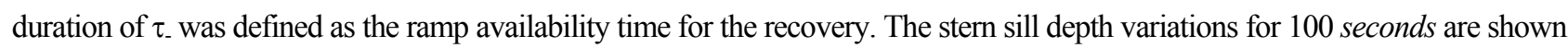
in Fig. 14 for the head sea condition and Fig. 15 for the following sea condition, which are picked from ten trials of each condition.

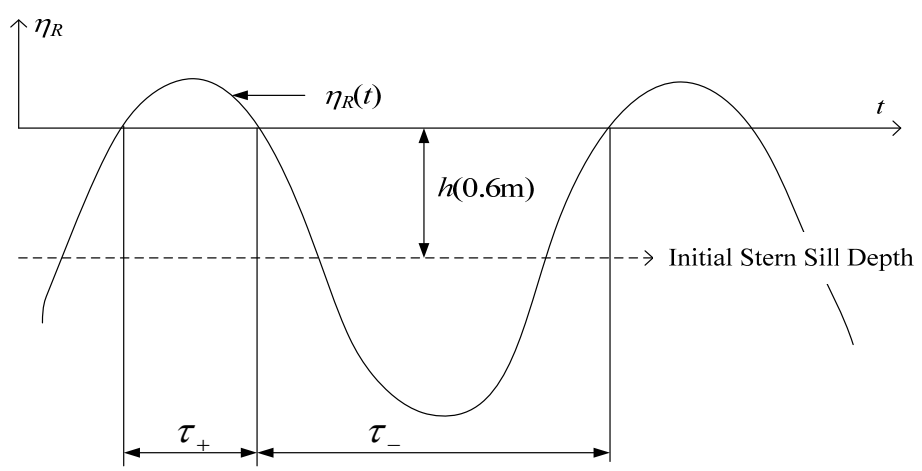

Fig. 13 Definition sketch for stern sill depth.

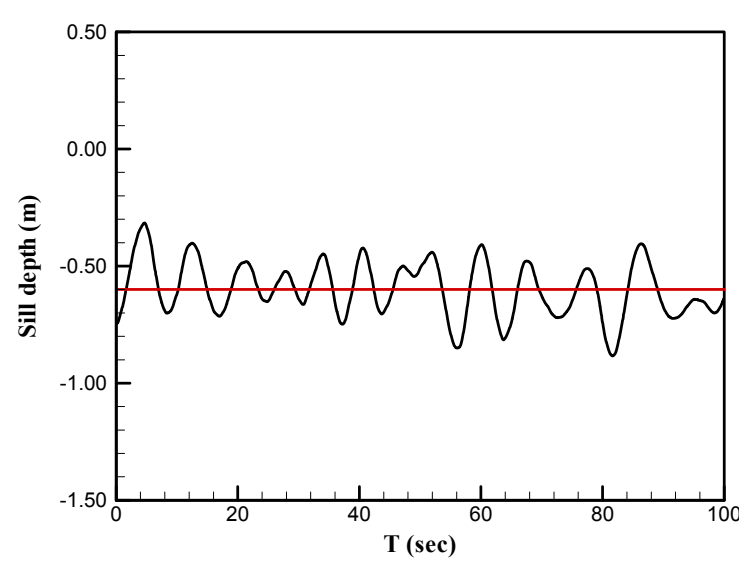

(a) 5 knots in sea state 3 .

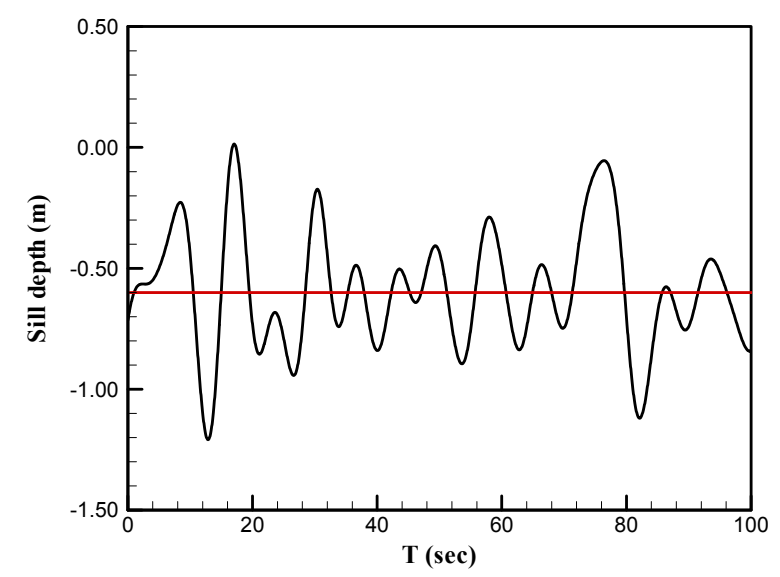

(c) 5 knots in sea state 4 .

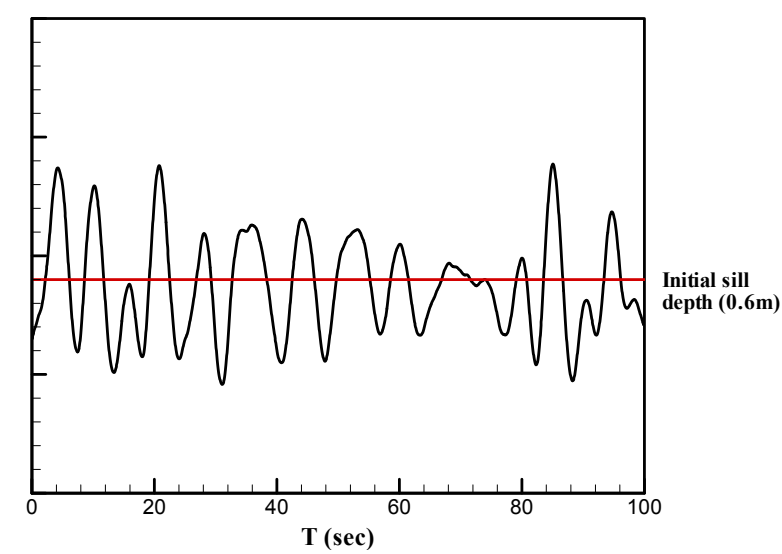

(b) 8 knots in sea state 3 .

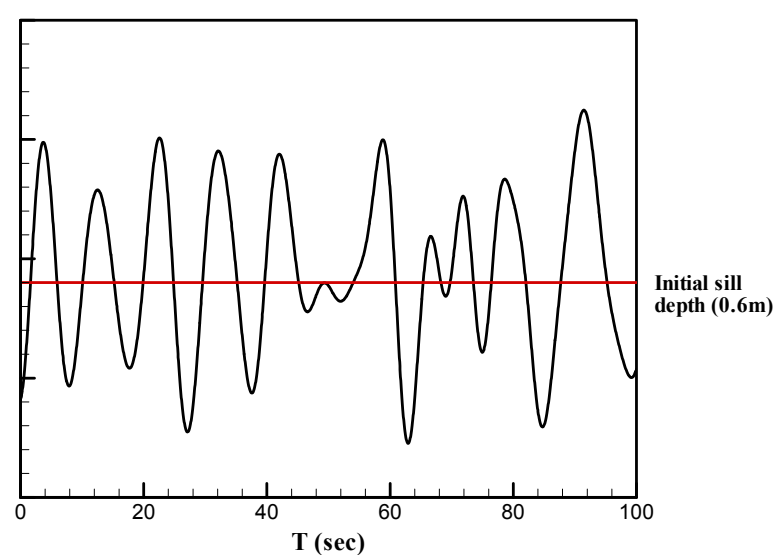

(d) 8 knots in sea state 4 .

Fig. 14 Stern sill depth variation in head sea.

The percentage of ramp availability time obtained from all trials for each case is summarized in Table 8 . In Sea State 3 , the stern ramp was available with $100 \%$ time duration to recover RHIB for both speeds. However, the ramp availability time was reduced in higher Sea State and faster speed. In the following sea, the percentage of ramp available time $(96.9 \%$ and $96.4 \%$ for 5 and 8 knots, respectively) was larger than $91.8 \%$ and $89.3 \%$ for 5 and 8 knots in the head sea. Also, the pattern of stern sill 
variations in the following sea would be more regular and expectable than those in the head sea as shown in Fig. 14 and Fig. 15. That is, the recovery of RHIB can be preceded with the $100 \%$ ramp availability time in Sea State 3 . In Sea State 4 , the coxswain should carefully observe the stern ramp motion and determine the moment to recover RHIB.

Table 8 Percentage of ramp availability time during RHIB recovery.

\begin{tabular}{|c|c|c|c|}
\hline \multirow{2}{*}{ Sea state } & \multirow{2}{*}{ Speed (knots) } & \multicolumn{2}{|c|}{ Percentage of ramp availability time } \\
\cline { 2 - 4 } & & Head sea & Following sea \\
\hline \multirow{2}{*}{3} & 5 & $100.0 \%$ & $100.0 \%$ \\
\cline { 2 - 4 } & 8 & $100.0 \%$ & $100.0 \%$ \\
\hline \multirow{2}{*}{4} & 5 & $91.8 \%$ & $96.9 \%$ \\
\cline { 2 - 4 } & 8 & $89.3 \%$ & $96.4 \%$ \\
\hline
\end{tabular}

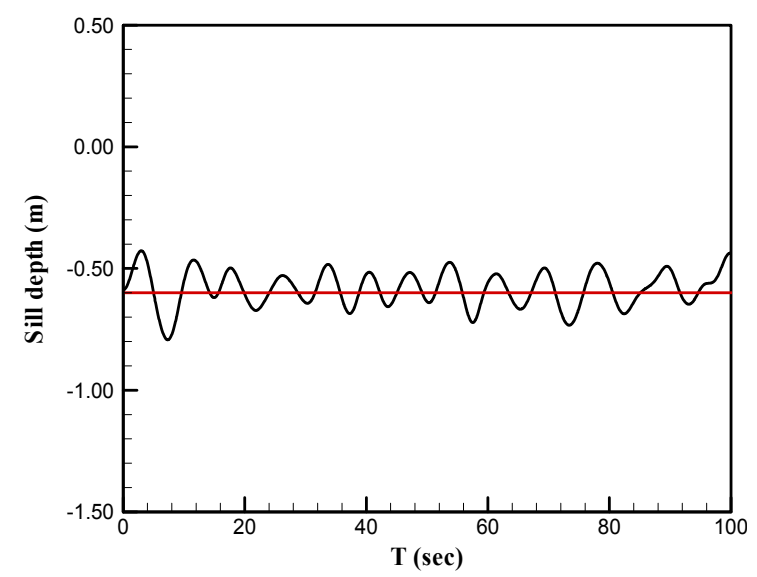

(a) 5 knots in sea state 3 .

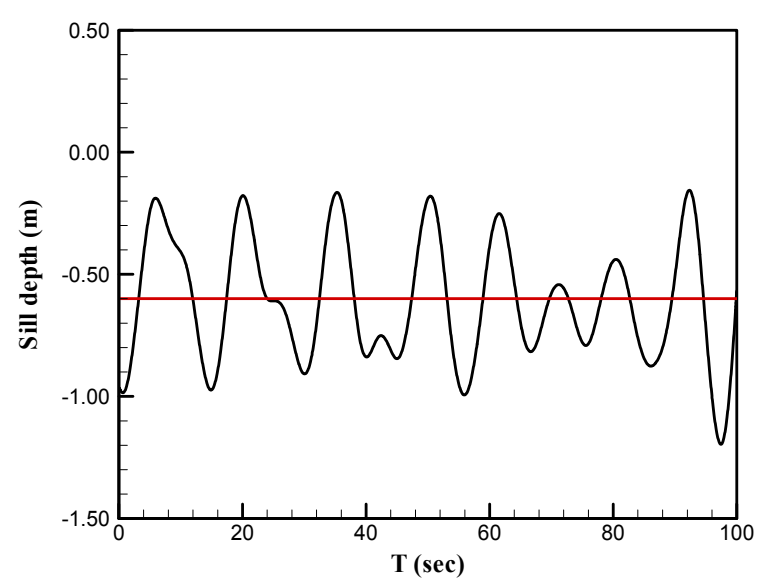

(c) 5 knots in sea state 4 .

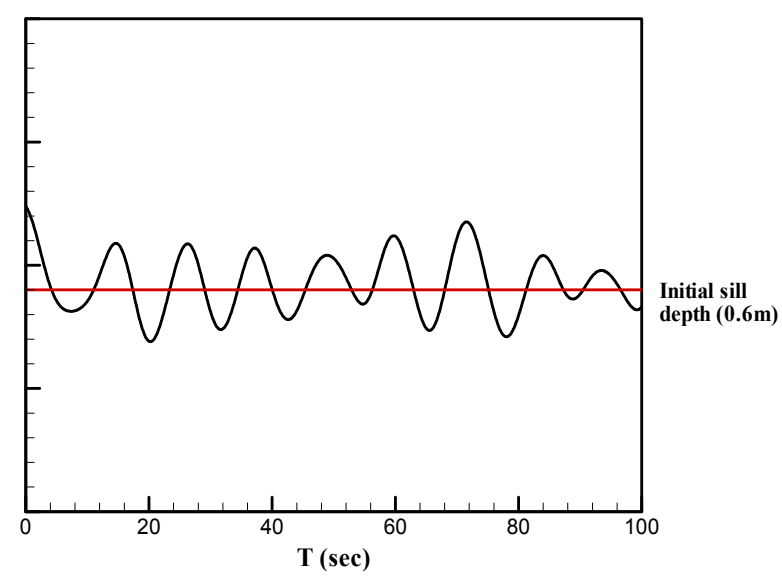

(b) 8 knots in sea state 3 .

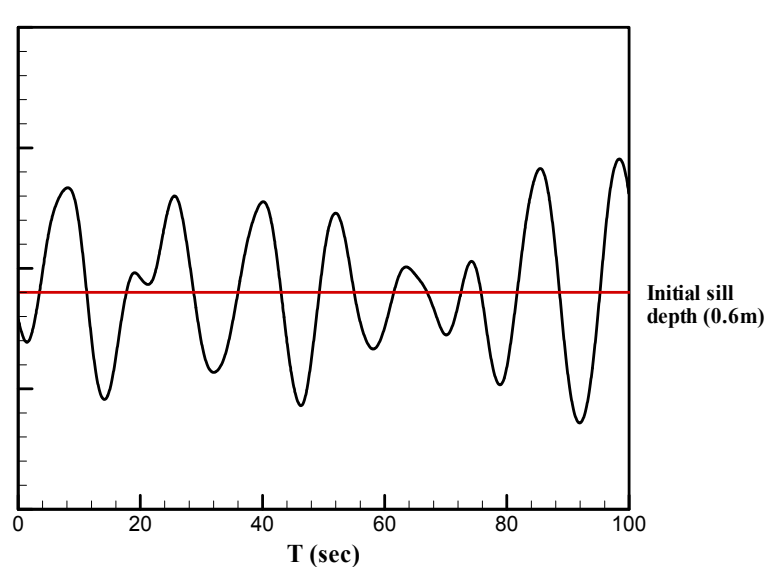

(d) 8 knots in sea state 4 .

Fig. 15 Stern sill depth variation in following sea.

\section{Time duration for launching and recovery}

The time duration of launching and recovery RHIB was measured for 10 trials for each condition and the results of mean duration and standard deviation in full scale are summarized in Table 9. The recovery time duration was defined as spending time to complete the recovery after the recovery order at approximate distance $100 \mathrm{~m}$ ( $8 \mathrm{~m}$ in model tests) from the stern ramp. And, launching time duration was defined as time length for which RHIB went away from the stern wake zone and self-drove 
after launching order. The launching procedure was completed within approximate 10 seconds for all conditions. The recovery time duration shows the approximate 10 seconds difference between 5 and 8 knots for both Sea States. The reason is that, with 8 knots, the stronger water jet flow and the steeper stern wave increased the resistance of RHIB and reduced its maneuverability and sea-keeping abilities during approaching to the stern ramp. From several recovery missions at 8 knots in Sea State 4, RHIB was hit by the water jet and pushed away out of the recovery course. Then, RHIB turned around and tried again to complete the recovery procedure which was resulted into the relatively large standard deviation. Only two trials of recovery tests were succeeded within 30 seconds.

Table 9 Time duration for RHIB launching and recovery ( $1^{\text {st }}$ number: in head sea, $2^{\text {nd }}$ number: in following sea).

\begin{tabular}{|c|c|c|c|c|c|}
\hline \multirow{2}{*}{ Sea State } & \multirow{2}{*}{ Speed (knots) } & \multicolumn{2}{|c|}{ Recovery time duration $(s)$} & \multicolumn{2}{|c|}{ Launching time duration $(s)$} \\
\hline & & Mean & STDV & Mean & STDV \\
\hline \multirow{2}{*}{3} & 5 & $17.4,17.7$ & $2.4,2.7$ & $7.3,7.7$ & $2.3,2.7$ \\
\hline & 8 & $27.1,27.5$ & $7.6,11.6$ & $8.1,8.2$ & $2.6,4.5$ \\
\hline \multirow{2}{*}{4} & 5 & $18.7,20.6$ & $1.9,3.0$ & $5.0,6.3$ & $1.3,1.9$ \\
\hline & 8 & $37.1,30.5$ & $10.1,17.8$ & $\mathrm{~N} / \mathrm{A}, 8.0$ & $\mathrm{~N} / \mathrm{A}, 1.4$ \\
\hline
\end{tabular}

\section{Launching and recovery courses}

The coordinate of RHIB was obtained by the optical tracking system (RODYM DMM-6D) during the launching and recovery procedure. The coordinate of launching and recovery courses was averaged from 10 trials for each test condition and represented over the images of transom zone showing the stern wake and the water jet flow. Fig. 16 represents the launching

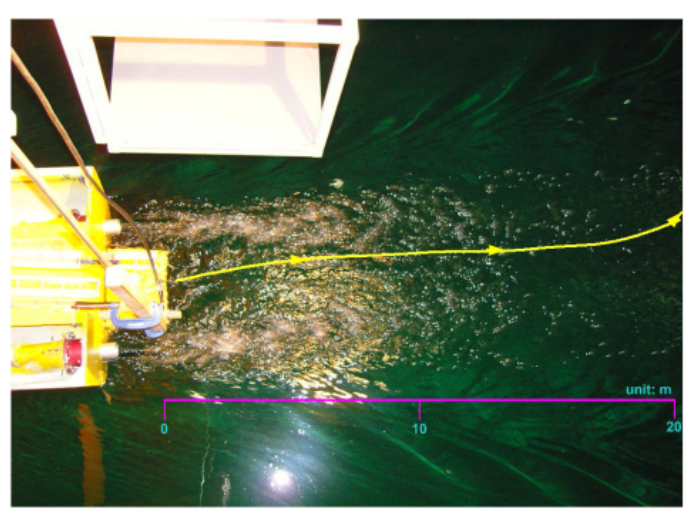

(a) 5 knots in sea state 3 .

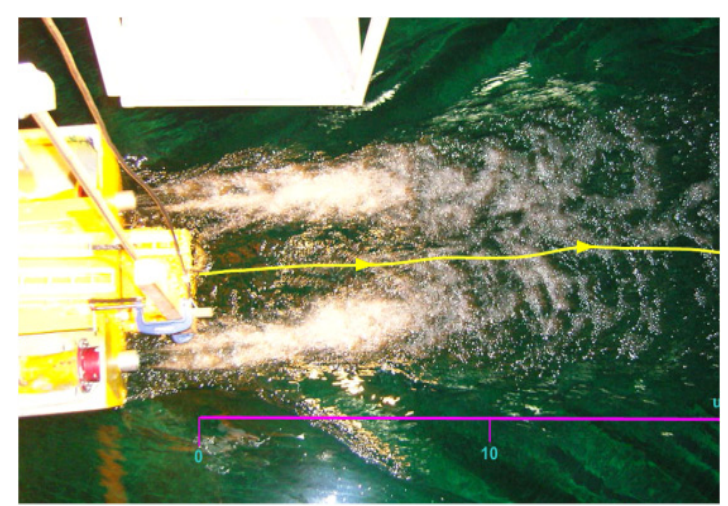

(b) 8 knots in sea state 3 .

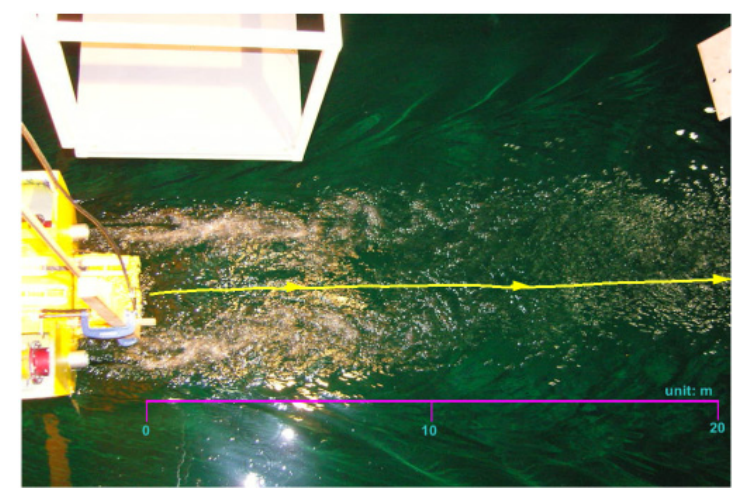

(c) 5 knots in sea state 4 .

Fig. 16 RHIB launching trajectory. 
courses which went through between two water jet flows. When RHIB was released from the winch motor, it slid down on the rail and stuck by the displacement of its transom partly submerged under the water. Then, it self-propelled to reverse direction through two water jet flows. The recovery courses are shown in Fig. 17 which RHIB drove through the stern wake zone between two water jet flows and approached to the stern ramp. When the mother ship ran with 8 knots, it shows the strong water jet flows ejected from jet nozzles.

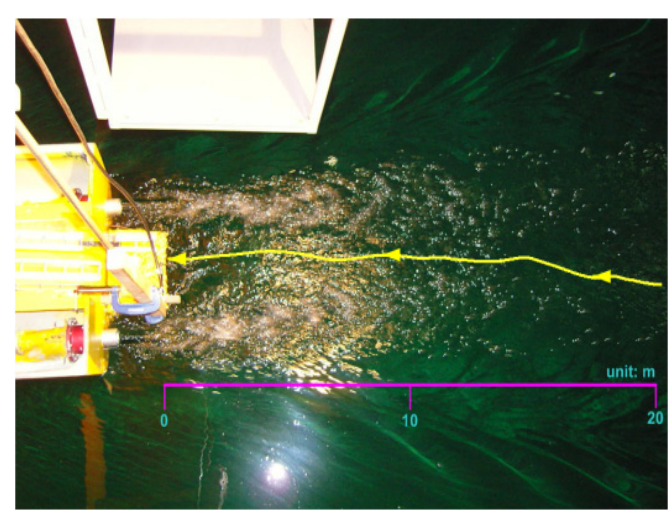

(a) 5 knots in sea state 3 .

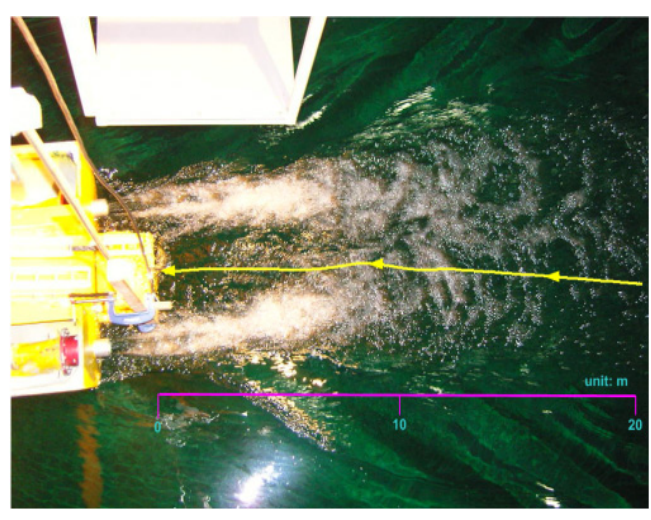

(b) 8 knots in sea state 3 .

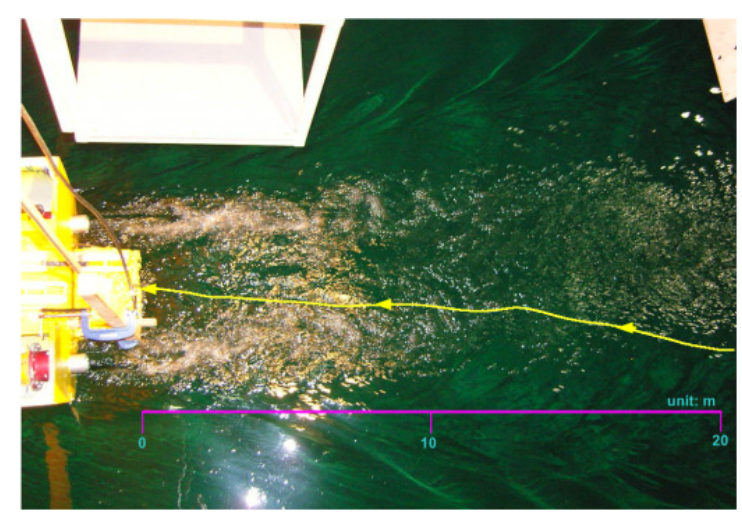

(c) 5 knots in sea state 4 .

Fig. 17 RHIB recovery trajectory.

\section{Experimental PTO test}

The experimental percent time operability (PTO) test was performed by 10 trials for each condition varying the wave direction, the speed, and Sea State. PTO test results are summarized in Table 10. From tests with 5 and 8 knots in Sea State 3 and 5 knots in Sea State 4, the launching and recovery test obtained $100 \%$ of success possibility. With 8 knots in Sea State $4,80 \%$ and $90 \%$ of recovery trials successfully completed in the head sea and the following sea, respectively. The reason is that the strong

Table 10 PTO test results.

\begin{tabular}{|c|c|c|c|c|c|}
\hline \multirow{2}{*}{ Sea State } & \multirow{2}{*}{$\begin{array}{c}\text { Speed } \\
\text { (knots) }\end{array}$} & \multicolumn{2}{|c|}{ Percentage of recovery success (\%) } & \multicolumn{2}{c|}{ Percentage of launching success (\%) } \\
\cline { 2 - 6 } & 5 & Head sea & Following sea & Head sea & Following sea \\
\hline \multirow{3}{*}{3} & 8 & 100 & 100 & 100 & 100 \\
\cline { 2 - 6 } & 5 & 100 & 100 & 100 & 100 \\
\hline \multirow{3}{*}{4} & 8 & 100 & 100 & 100 & 100 \\
\hline
\end{tabular}


water jet was fluctuated by the mother ship and disturbed RHIB approaching to the stern ramp. Because the resistance of RHIB was increased to go through water jet flows and go over the stern wave and the maneuvering and sea-keeping abilities of RHIB were reduced by turbulent flow within the transom zone, it took longer time duration to complete the recovery procedure. The experimental PTO test results are reasonably agreed with the percentage of the ramp availability time which was shown higher successful possibility in the following sea than in the head sea.

\section{CONCLUSION}

The experimental investigation was performed to test the stern ramp deployment system of KCG 500 ton class fast patrol ship with three evaluation categories. The first compared the motion characteristics of mother ship with suggested design criteria similar with the side-davit system criteria. The second was the stern ramp availability criterion that was quantified with the stern sill depth variation. The third was proposed with the recovery course of RHIB approaching to the stern ramp which minimized the combined hydrodynamic effect of the stern flow and the water jet. The stern flow pattern depends on the propulsion system type because the screw propeller and the water jet generate the different flow pattern with the velocity profiles and turbulence strength. The single significant amplitude (SSA) of the pitch motion at the condition of 5 knots in head and following sea on Sea State 4 was over the suggested design criterion. In these conditions, the launching and recovery test succeeded $100 \%$ from the PTO test without any difficulties. However, the recovery trials were successful for $80 \%$ in head sea and $90 \%$ in following sea with 8 knots in Sea State 4 even though the pitch motion SSAs were smaller than those of 5 knots in Sea State 4 . In addition, their recovery time duration was 10 20 seconds longer than 5 knots in Sea State 4 and the recovery procedures was more hazardous. The percentage of ramp availability time obtained from the stern sill depth variation reasonably agreed with PTO test results. The suggested design criteria was adapted from the side-davit deployment system, but the deployment mechanism was not similar each other. Because the motion characteristics of the mother ship is important to assess the stern ramp operation, the design criteria for the mother ship motion should be reviewed for the deployment via the stern ramp by surveying the motion characteristics of the well-operating existing vessels equipped the stern deployment system and expanded experimental studies. When RHIB approached to the stern ramp, it experienced the resistance increasing and loosing the maneuvering and sea-keeping ability in the recovery course due to the combined hydrodynamic effect of the stern wake and wave and the water jet flow. Especially, the water jet fluctuating by the mother ship motion can give a serious damage to RHIB in the transom zone in higher sea state. RHIB should overcome the additional resistance resulting from the stern wave and the water jet and choose the recovery course to maintain the directional control within the strong turbulent zone near the transom. To perform the launch and recovery mission, the mother ship is recommended to cruise with speeds between 3 and 6 knots and RHIB with 6 12 knots. This speed range can maintain the mother ship's course and slow enough for RHIB to run away from the stern wake turbulence zone immediately after launch. With cruising in this speed range, RHIB is able to be recovered the course between tow water jets in head or following seas to $30^{\circ}$ off the wave crest lines. The RHIB coxswain should choose the safe recovery course to minimize the combined hydro-dynamic effect and maintain the directional control ability. He would decide the speed approaching to the stern ramp and the ramp available moment having the stern sill depth enough to recovery. That is, the successful performance of RHIB deployment depends greatly on the coxswain's experience and proficiency that can understand the ocean environment and the ship's behavior. Hands-on simulation-based training in a model basin would help the coxswain acquire the skill to cope with the various combined ocean conditions before facing the challenge in the real seaway.

\section{ACKNOWLEDGEMENTS}

This work was supported by Hanjin Heavy Industries \& Construction Co. Ltd. and the National Research Foundation of Korea (NRF) grant funded by the Korea government (MEST) through GCRC-SOP.

\section{REFERENCES}

Clauss, G.F. and Kauffeldt, A., 2006. Investigation and optimization of boat deployment systems at high seas, OMAE. $25^{\text {th }}$ International Conference on Offshore Mechanics and Arctic Engineering. Hamburg, Germany 4-9 June 2006. 
Dalzell, J.F., 2003. A Proposed criterion for launch ramp availability, Hydromechanics Directorate Technical Report NSWCCD-50TR-2003/15. [online] Available at: <http://www.dtic.mil/cgi-bin/GetTRDoc?Location=U2\&doc=GetTRDoc. pdf\&AD $=$ ADA414466 $>$ [Accessed 11 November 2006].

Minnick, P.V., Cleary, C. and Sheinberg, R., 1999. Operational comparison of the 270-ft WMEC and 378-ft WHEC based on full scale seakeeping trials. Society of Naval Architects and Marine Engineers Chesapeake Section. Baltimore, Maryland, United States of America 16 June 1999.

Sheinberg, R., Cleary, C. and Beukema, T.G., 2001. Worldwide assessment of stern launch capability. 24 ${ }^{\text {th }}$ United States Japan Cooperative Program in Natural Resources (U.S./UJNR) Marine Facilities Panel Meeting. Honolulu, Hawaii, United States of America 7-8 November 2001.

Sheinberg, R., Minnick, P.V., Beukema, T.G., Kauczynski, W., Silver, A.L. and Cleary, C., 2003. Stern boat deployment systems and operability. World Maritime Technology Conference. San Francisco, United States of America 17-20 October 2003 . 